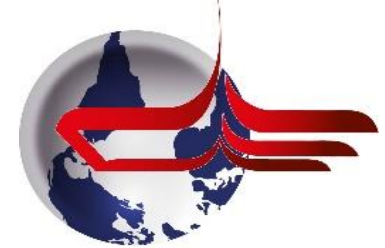

TURK-TES

\title{
Eğitim Alanı Nitel Araştırmalarında Veri Üçgenlemesi Olarak Odak Grup Görüşmesi, Bireysel Görüşme ve Gözlem
}

\author{
Ece IŞIK ${ }^{1}$
}

Çetin SEMERC $\dot{\mathbf{I}}^{2}$

\section{$\ddot{O} \mathbf{z}$}

Günümüzde eğitim araştırmalarında sıklıkla kullanılan nitel araştırmalar insanların deneyimlerini nasıl yorumladıkları, dünyalarını nasıl yapılandırdıkları ve deneyimlerine ne anlamlar yükledikleri ile ilgilenir. Nitel araştırmaların kendilerine özgü özellikleri vardır. Nitel araştırmalar naturalistik, tanımlayıcı, süreçle ilgili, tümevarımsal ve anlamın önemli olduğu çalışmalardır. Bu özelliklerinden dolayı nitel araştırmalarda yanlış algılamayı ve sonuçların geçersizliğini en aza indirmek için üçgenleme kullanılır. Üçgenleme, doğruluğu arttırmak için bir şeye çoklu bakış açısı ile bakmak anlamına gelir. Bu bağlamda nitel araştırmalarda veri üçgenlemesi olarak odak grup görüşmesi, bireysel görüşme ve gözlem kullanılabilir. Bu çalışmanın amacı, nitel araştırmalarda kullanılan odak grup görüşmeleri, bireysel görüşmeler ve gözlemleri tanıtmak ve veri üçgenlemesi olarak nasıl kullanıldığını betimlemektir. Odak grup görüşmeleri araştırmacının süreç içerisindeki sosyal etkileşimleri görmesini sağlar. Odak gruplar belirli bir şekilde yapılandırılmış, grup görüşmeleridir. Bireysel görüşme ise bir kişinin bilgi edinmek amacı ile diğerine soru yöneltmesidir. Bireysel görüşme tanımlayıcı veri elde etmek için kullanılır. Böylece, araştırmacı katılımcıların kendi dünyalarını nasıl yorumladıkları ile ilgili iç görü geliştirebilir. Bu çalışmada veri üçgenlemesi olarak kullanılan son yöntem olan gözlem yoluyla araştırmacı katılımcıların günlük uygulamalarını belgeleyerek, onların deneyimlerini daha iyi anlamaya çalışır. Nitel araştırmalarda odak grup görüşmesi, bireysel görüşme ve gözlemin birlikte kullanılması, araştırmada büyük resmi ortaya koymada yardımcı olur.

Anahtar Kelimeler: Nitel araştırma, odak grup görüşmesi, bireysel görüşme, gözlem.

\section{Focus Group Interviews, Individual Interviews and Observations As Data Triangulation In Qualitative Studies In Education}

\footnotetext{
${ }^{1}$ İngilizce Öğretmeni, Mimar Sinan ÇPAL, Hatay, Türkiye, ecemeral@ yahoo.com

2 Prof. Dr., Bartın Üniversitesi Eğitim Fakültesi, Bartın, Türkiye, csemerci@bartin.edu.tr
} 


\begin{abstract}
Qualitative studies, frequently used in educational researches nowadays, are interested in how people interpret their own experience, how they construct their own worlds and which meanings they put their experience on. Qualitative studies have their own features. They are naturalistic, defining, engaged in the process, inductive and meaning focused studies. In order to minimize misunderstanding and results' invalidity, triangulation is used in qualitative studies. Triangulation is to examine something from multiple angels to maximise the accuracy. In this sense focus group interviews, interviews and observations are used as data triangulation in qualitative studies. The aim of this study is to define focus group interviews, individual interviews and observations in qualitative studies and to describe how they are used as data triangulation. Focus group interviews make the researcher understand the social interactions during the process. In interviews, a person asks a question to another person to gain information. In observations, the researcher documents the attendants' daily practices and try to understand better their experience. The use of focus group interview, individual interview and observation together in qualitative research helps to reveal the big picture in the research.
\end{abstract}

Keywords: Qualitative studies, focus group interviews, individual interviews, observations

\title{
1. Giriş
}

Nitel araştırmalar, sosyoloji, antropoloji ile başlayıp, daha sonra eğitim, iletişim gibi diğer sosyal bilimlerde de uygulanmaya başlanmıştır. Nitel araştırma beş tarihi döneme ayrılmıştır. Bu beş dönem günümüzde eş zamanlı olarak işlemeye devam etmektedir. Bu dönemler geleneksel (1900-1950), modernist ya da altın çağ (1950-1970), bulanık türler (1970-1986), temsil krizi (1986-1990) ve postmodern ya da günümüz tarihidir (1990-günümüz) (Denzin ve Lincoln, 1998, 2). Epistemolojik teorilerin başarılı dalgaları bu beş dönem etrafında hareket etmektedir. Geleneksel dönem pozitivist paradigma ile ilişkilidir. Modernist ya da altın çağ ve bulanık türler post pozitivist argümanlarla bağlantılıdır. Postmodern dönem ise önceki paradigmalardan farklıdır. Günümüzde yapılandırmacılık kuram ve felsefelerinden etkilenilmektedir. Merriam'a $(2009,14)$ göre, yapılandırmacılık, fenomenoloji ve sembolik etkileşim felsefelerinden etkilenen nitel araştırmalar insanların deneyimlerini nasıl yorumladıkları, dünyalarını nasıl yapılandırdıkları ve deneyimlerine ne anlamlar yükledikleri ile ilgilenir. Bu anlamda, yapılan araştırmalarda büyük resmi daha iyi ortaya koyabilmek için araştırmanın amacı olarak, nitel araştırmalarda kullanılan odak grup görüşmeleri, bireysel görüşmeleri ve gözlemleri tanıtmak ve veri üçgenlemesi olarak nasıl kullanıldığını betimlemek şeklinde belirlenmiştir. Öncelikle nitel araştırmalar ve üçgenleme üzerinde durulmuştur.

Nitel Araştırma ve Üçgenleme

Nitel araştırmalar, olayları ve olguları doğal ortamları içinde betimleyerek katılanların bakış açılarını anlamak ve yansıtmak üzerine odaklanan tümevarımsal bir araştırma yaklaşımıdır. (Yıldırım ve Şimşek, 2008). Nitel araştırmaların beş özelliği Şekil 1'de verilmiştir (Bogdan ve Biklen, 1998, 4-7): 


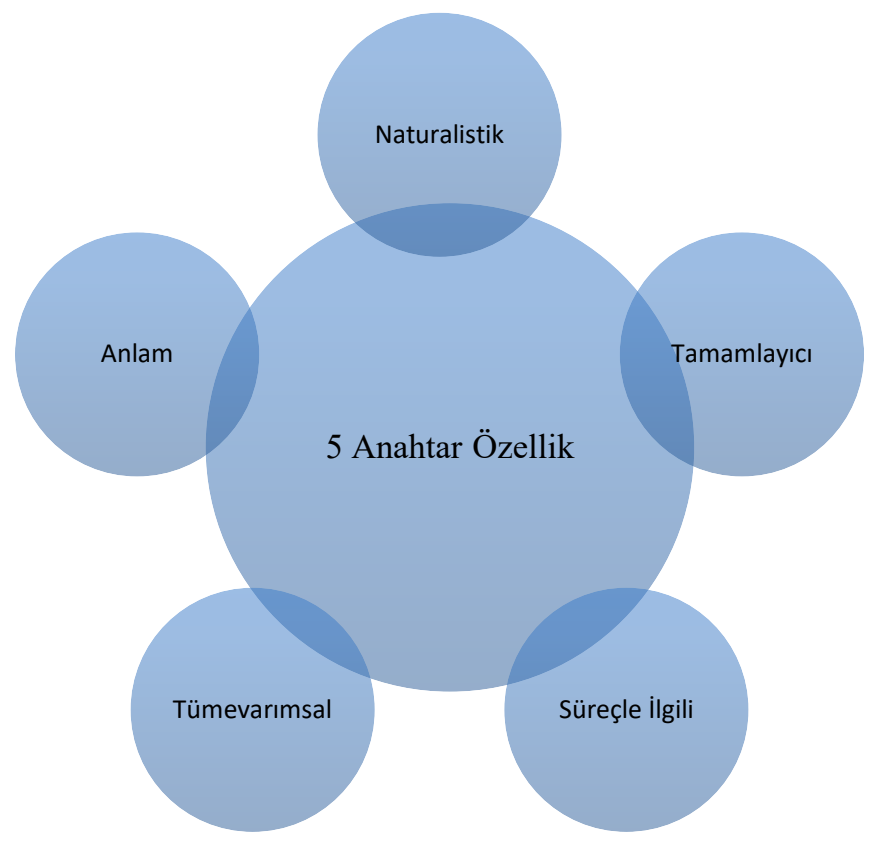

Şekil 1. Nitel araştırmanın beş anahtar özelliği

Nitel araştırmaların beş anahtar özelliği Şekil 1'de sunularak aşağıda açıklanmaya çalışılmıştır (Bogdan ve Biklen, 1998, 4-7):

1.Nitel araştırmalar naturalistiktir: Nitel araştırmada direkt veri kaynağı olarak gerçek ortamlar vardır ve araştırmacının kendisi anahtar enstrümandır.

2. Nitel araştırmalar tanımlayıcıdır: Toplanan veri sayılardan çok kelime ya da resim şeklindedir. $\mathrm{Bu}$ verilere görüşme transkriptleri, saha notları, fotoğraflar, video kayıtları, kişisel dokümanlar ve diğer resmi kayıtlar dahildir. Nitel yaklaşımda hem veri kayıtlarında hem de bulguları açıklamada yazılı kelimeler oldukça önemlidir.

3.Nitel araştırmalar süreçle ilgilidir: Nitel araştırmalarda sonuç ya da üründen çok süreçle ilgilenilir. Nitel stratejiler beklentilerin günlük aktivitelere, prosedürlere ve etkileşimlere nasıl çevrilmesi gerektiğini önerir.

4.Nitel araştırmalar tümevarımsaldır: Nitel araştırmacılar verileri tümevarımsal olarak analiz ederler. Çalışmaya başlamadan önce ortaya koyulan hipotezleri kanıtlamak ya da çürütmek için veri ya da kanıt toplamazlar. Aksine bir araya getirilen özelliklerin birlikte gruplanması ile soyutlamalar oluşturulur. Veri analiz süreci bir huniye benzer. Başlangıçta her şey açıktır, bitime doğru ise daha direkt ve belirgindir. 
5.Anlam: "Anlam” nitel yaklaşımda oldukça önemlidir. Nitel araştırmacılar farklı insanların hayatlarını nasıl yaşadıkları ve perspektifleri doğru bir şekilde yakaladıklarından emin olmakla ilgilenirler.

Nitel araştırmalarda yanlış algılamayı ve sonuçların geçersizliğini en aza indirmek için üçgenleme kullanılır (Stake, 1995, 134). Üçgenleme terimi orijinalde trigonometrinin navigasyon ve ölçmeye uygulanması ile alanyazına girmiştir. Bir haritada kişinin kesin pozisyonu sadece uzaklıktaki bir nesne olarak belirlenemez. Bu, kişinin yerini sadece bir çizgi üzerinde belirler. İkinci bir nesneye de ihtiyaç duyulur. Böylece iki varlığın kesişimi ile birinci kişinin yeri belli olur (Bogdan ve Biklen, 1998, 104). Benzer şekilde üçgenleme kavramı daha çok seyahatleri organize etme veya arazi etütlerinde iki veya üç ölçüm noktasının belirli bir şekilde birleştirilmesi ile ilgilidir (Merriam, 2015, 205). Çoklu veri araçlarının kullanılarak elde edilen verilerin çapraz sorgulanması anlamına gelir (Akar, 2016, 132; Atkins ve Wallace, 2012, 111; McCormick ve James, 1990, 19; Naumes ve Naumes, 1999, 50; White, 1988, 15). Sosyal bilimlerde üçgenlemede amaç veri toplama araçları arasında tam olarak örtüşme olduğunu göstermek değildir. Amaç farklı bakış açıları ile elde edilen sonuçları karşılaştırmaktır (Mayring, 2011, 148). Üçgenleme genellikle anlamı açıklamak, bir gözlem ya da yorumun tekrar edilebilirliğini doğrulamak için çoklu alg1 kullanma sürecidir (Stake, 1998, 97). Bir başka tanıma göre üçgenleme, doğruluğu arttırmak için bir şeye çoklu bakış açısı ile bakmak anlamına gelir (Neuman, 2014, 166). Aynı olguya farklı ölçme yaklaşımları ile bakan ölçme üçgenlemesi eğitim ve sosyal bilimlerde en yaygın kullanılan üçgenleme türüdür.

Üçgenleme sosyal bilimlerde ilk kez bir bilgiyi ortaya koymada tek kaynaklı bilgiden daha fazlasına ihtiyaç duyulduğunda kullanılmaya başlanmıştır. Bir çalışma için çok kaynaklı veriler daha anlamlıdır çünkü çoklu kaynaklar çalışılan olgunun tam olarak anlaşılmasını sağlar (Bogdan ve Biklen, 1998, 104). Üçgenleme çalışılan olgunun derinlemesine anlaşılmasını sağlar. Bu bağlamda nitel araştırmalarda veri üçgenlemesi olarak odak grup görüşmesi, bireysel görüşme ve gözlem kullanılabilir. 


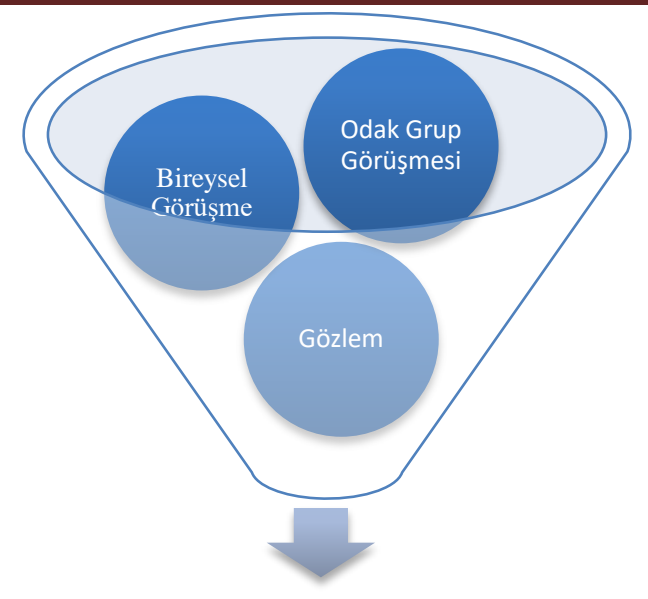

Veri Üçgenlemesi

Şekil 2. Veri üçgenlemesi yöntemleri

Şekil 2'de görüldüğü gibi odak grup görüşmesi, bireysel görüşme ve gözlem yöntemleri kullanılarak nitel araştırmalarda veri üçgenlemesi yapılarak çalışmaların doğruluğu arttırılabilir ve çalışılan olgu tam olarak anlaşılabilir. Bu çalışmada veri üçgenlemesi yöntemleri olarak odak grup görüşmeleri, bireysel görüşmeler ve gözlemler ayrı başlıklar altında tanımlanmıştır.

\section{Odak Grup Görüşmesi}

Günümüzde sosyal bilimler araştırmacılarının nitel veri toplamak için sıklıkla kullandığı yöntemlerden bir tanesi de odak grup görüşmeleridir (Kamberelis ve Dimitriadis, 2005, 898; Knodel, 1993, 35; Mertens, 2005, 245; Stewart ve Shamdasani, 1990, 9). Pratik bir şekilde uygulanabilir olması ve kullanışlılığı veri toplama yöntemi olarak odak grup görüşmelerinin kullanılmasında etkendir (SavinBaden ve Major, 2013, 374). Odak grup görüşmelerinin bireysel görüşmelerle bazı ortak noktaları olsa da işlev ve şekil bakımından birbirlerinden farklıdırlar. Odak grup görüşmeleri araştırmacının süreç içerisindeki sosyal etkileşimleri görmesini sağlar.

Odak gruplar belirli bir şekilde yapılandırılmış grup görüşmeleridir. Genellikle sekiz ya da on kişi ve bir moderatörden oluşur. Bir konu verilir ve katılımcılar önce sıra ile daha sonra dinamik grup diyaloğunun bir parçası olarak bu konu hakkında konuşmaları için cesaretlendirilir (Bogdan ve Biklen, 1998, 100). Odak gruplardaki ayırt edici nokta araştırmacı sorularına verilen cevaplardaki grup etkileşiminin varlığıdır (Morgan ve Krueger, 1993, 15). Odak gruplardaki etkileşim diğerlerinin nasıl düşündüğü ve konuştuğu hakkında net bir fikir ortaya koyar. Odak gruplardaki etkileşim diğer yöntem veya tekniklerden çok daha fazla bilgi edinilmesi açısından oldukça önemlidir. 
Odak grup görüşmesi araştırmacının sosyal süreçleri görmesine olanak sağlar. Bu nedenle, odak grup görüşmeleri dikkatli bir şekilde planlanır ve bir moderatör tarafından yönetilir (Savin- Baden ve Major, 2013, 375). Odak grup görüşmeleri sayesinde bazı bireylerin düşünceleri hakkında hızlı bir şekilde bilgi elde edilebilir. Odak grup görüşmelerinde sorular tek bir bireye değil, bütün gruba sorulur. Moderatör önceden oluşturulmuş ana hatlar doğrultusunda soruları ve yorumları doğaçlayarak odak grup çalışmasını sürdürmelidir. Soruları açık uçlu tutarak, moderatör katılımcılarda daha önceden tahmin edilemeyen düşünceleri canlandırmaya çalışır (Knodel, 1993, 36).

Odak grup görüşmelerinde moderatör, tartışmanın ana konudan sapmaması konusunda anahtar konumdadır. Moderatör grup dinamikleri ve görüşme becerileri konusunda yetenekli olmalıdır (Stewart ve Shamdasani, 1990, 10). Moderatör olmak sadece soru sormak ve verilen cevapları kaydetmek değildir. Tartışmanın akışını yönlendirmeden tartışmanın devam etmesini sağlayabilecek bir tür grup liderliği gerektirmektedir (Yıldırım ve Şimşek, 2008, 161).

Stewart ve Shamdasani’ye $(1990,16)$ göre, diğer araştırma türlerine kıyasla odak grup görüşmeleri birçok avantaj sunmaktadır. Odak grup görüşmeleri bireysel görüşmelere göre, bir grup insandan çok daha hızlı ve daha az maliyetle bilgi elde eder. Odak grup görüşmeleri araştırmacının katılımcılarla direkt olarak etkileşimde bulunmasına izin verir. $\mathrm{Bu}$ ise cevapların netleştirilmesi, görüşme sonrası sorular gibi birçok konuda olanaklar sunar. Odak grup görüşmeleri ile nicel veri elde edilebilmesine rağmen, bu tür görüşmelerin ilk amacı nitel veri toplamaktır. Bu bir avantajdır, çünkü odak grup görüşmeleri katılımcıların kendi kelimeleri ve bağlamlarında oldukça zengin veriler sunar. Anket çalışmalarının aksine, verilen cevapların daha samimi olduğu söylenebilir. Katılımcılar kendi cevaplarını nitelendirebilir ya da cevapları ile ilgili önemli olasılıkları tanımlayabilirler. Böylece, cevapların geleneksel anket çalışmasında bulunmayan yönleri ortaya çıkmış olur. Bunun yanında araştırmacı sözel olmayan jest, mimik, gülümseme, kızgınlık gibi ifadeleri de göz önünde bulundurabilir.

Araştırmacı daha derin anlamlar elde edebilir, önemli bağlantılar kurabilir ve ifade ile anlam arasındaki küçük farklılıkları tanımlayabilir (Yıldırım ve Şimşek, 2008, 163). Odak grup görüşmelerinde katılımcılar diğer grup üyelerinin cevaplarına göre kendi cevaplarını yapılandırabilirler. Odak grup görüşmeleri çok esnektir. Birçok konuda, birçok bireyle ve birçok ortamda kullanılabilirler. Odak grup görüşmeleri çocuklardan ya da okuma yazma bilmeyen bireylerden veri toplamak için kullanılan çok az araştırma yönteminden biridir (Stewart ve Shamdasani, 1990, 16). Odak grup görüşmesi sonuçlarını anlamak kolaydır. Araştırmacılar birçok katılımıının sözel cevaplarını anlamaya hazır durumdadır.

Odak grup görüşmelerinin başlangıcında bazı katılımcılar konuyla ilgili kendi fikirlerini, hislerini direkt söylemeyebilirler, diğerlerinin konuşmalarını duydukça, duyduklarının kendi durumları ile ne kadar 58 
örtüştüğünü kolayca tanımlayabilirler (Morgan ve Krueger, 1993, 17). Odak grup görüşmelerinde etkileşim diğer yöntemlerde olduğundan çok daha fazla bilgi edinilmesi açısından oldukça önemlidir. Böylece grup etkileşimi çalış1lan konuyu keşfetmek için sağlam bir temel oluşturur.

Odak grup görüşmelerinde katılımcıların kendilerini istedikleri gibi ifade etmelerine izin verilir, bu durum konuyu anlamayla ilgili daha geniş iç görü sağlar (Savin- Baden ve Major, 2013, 389). Bunun yanında, odak grup görüşmelerinde katılımcılar grup içinde direkt odak noktası olmadıkları için kendilerini daha rahat hissetmekte ve daha samimi cevaplar vermektedir (Menter, Elliot, Hulme, Lewin ve Lowden, 2011, 150).

Odak grup görüşmelerinin birçok avantajı bulunmasına rağmen, bütün araştırma ihtiyaçlarını karşılayan mucizevi bir çözüm değildir ve kendi sınıllılıkları bulunmaktadır (Stewart ve Shamdasani, 1990, 17). Odak grup görüşmeleri birbiriyle etkileşim halinde bulunan kısmen az sayıda katılımcıdan elde edilen nitel veriler sağlamaktadır. Odak grup görüşmelerinin amacı da tam olarak budur. Bulgular, nicel bir araştırmada olduğu şekliyle genellenemez. Diğer taraftan, bu çalışmanın nitel yöntem olduğu ve nicel çalışmalardaki şekliyle zaten genelleme yapılamayacağı bu sınırlılığın olmadığını düşündürebilir. Odak grup görüşmelerini planlamak ve yönetmek kolay değildir (Yıldırım ve Şimşek, 2008, 164).

\section{Bireysel Görüşme}

Bireysel görüşme bir kişinin bilgi edinmek amacı ile diğerine soru yöneltmesidir (Bogdan ve Biklen, 1998, 93). Bireysel görüşme katılımcılardan kendi kelimeleri ile tanımlayıcı veriler elde etmek için kullanılır. Böylece, araştırmacı katılımcıların kendi dünyalarını nasıl yorumladıkları ile ilgili iç görü geliştirebilir. Derinlemesine görüşmenin amacı sorulara cevap almak, hipotezleri test etmek ya da değerlendirme yapmak değildir. Derinlemesine görüşmenin temelinde, diğer insanların yaşadıkları deneyimleri anlamaya ve o deneyimi anlamlandırmaya olan ilgi vardır (Seidman, 2006, 9). Görüşme yapan kişiler katılımcıların sorulara verdikleri yanıtları dinlerken onların hikayelerinin önemli olduğunu hissettirirler.

Araştırmacı görüşme yaparken kendi endişelerini, umutlarını, kör noktalarını, önyargılarını, ırkını ya da cinsiyetini, küresel sosyal yapıdaki yerini, yaşını, duygularını ve daha birçok özelliğini geride bırakamaz. Bu durum görüşme yapılan kişiler için de geçerlidir. Görüşme sonunda elde edilen materyali analiz ederken de bireysel özellikler göz ardı edilemez (Wengraf, 2001, 4-5). Görüşme yapmak insan davranışlarını bağlamlarıyla birlikte görmeye ve böylece araştırmacılar için bu davranışları anlamaya olanak sağlar. Görüşme davranışı bağlamsallaştırmayı ve hareketin altında yatan anlamı öğrenmeyi 
sağlar. Görüşmeler katılımcının iş yerinde yapılmalıdır. Bu katılımcının daha güvenli hissetmesini sağlar. Aynı zamanda araştırmacı için de çalışılan durumun geçtiği çevre ile daha iyi bir anlama elde etmesine olanak tanır (Naumes ve Naumes, 1999, 49). Görüşmeler yapılandırma süreçlerine göre üç kategoriye ayrılmaktadır (Merriam, 2015, 87). Bunlar, tam yapılandırılmış, yarı yapılandırılmış ve yapılandırılmamış görüşmelerdir. Tablo 1'de yapılandırma süreçlerine göre görüşme türleri sunulmuştur.

Tablo 1. Yapılandırma Sürecine Göre Bireysel Görüşme Türleri

\begin{tabular}{lll}
\hline Tam Yapılandırılmış & Yarı Yapılandırılmış & Yapılandırılmamış \\
\hline Önceden belirlenmiş sorular & Yarı yapılandırılmış sorular & Açık uçlu sorular \\
\hline Soruların sırası belirli & Esnek sorular & Esnek, açıklayıcı sorular \\
\hline Yazılı araştırmanın sözel şekli & $\begin{array}{l}\text { Büyük kı kısmı açıklığa } \\
\text { kavuşturulması istenen sorular }\end{array}$ & Sohbet havasında \\
\hline Demografik değişkenler & Belirlenmiş ayrıntı yok & Olgu ile az şey bilindiği durumlar
\end{tabular}

Kaynak: Merriam'dan $(2015,87)$ uyarlanmıştır.

Tam yapılandırılmış görüşme soruların önceden belirlenerek sorulduğu, yazılı olarak yapılan araştırmaların sözlü ifade ediliş şeklidir (Merriam, 2015, 88). Yarı yapılandırılmış görüşmede eğer görüşmecilerden belirli bir bilgi elde etmek isteniyorsa yapılandırılmış görüşme teknikleri kullanılması uygundur. "Yarı yapılandırılmış" terimi bir dereceye kadar görüşme sorularının standartlaştırılmasını, bir dereceye kadar da bu soruların görüşmeyi yapan kişi tarafından cevaba açık bırakılmasını önerir (Wengraf, 2001, 62). Yarı yapılandırılmış görüşmeler araştırmacı ile katılımcılar arasında kıyaslanabilir veri elde edilmesi konusunda avantajıdır, diğer taraftan katılımcılar çalışılan konuyu kendilerinin nasıl yapılandırdığını öğrenme fırsatını kaybetmiş olur. Katılımcının kendi deneyimlediği dünyayı kendi görüşleri ile ifade etmesi istendiğinde daha az yapılandırılmış teknikler ve açık uçlu sorular sorulmalıdır (Merriam, 2015, 88). Yapılandırılmamış görüşmeler olgu ile çok fazla bilgiye sahip olunmadığı durumlarda yapılır ve genellikle sohbet havasındadır. Burada ne tür görüşmenin seçileceği yine araştırmanın amacına bağlıdır (Bogdan ve Biklen, 1998, 95). İyi bir görüşme katılımcı perspektiflerini ortaya çıkaran zengin veriler ile doludur.

\section{Gözlem}

Gözlem yüzyılı aşkın süredir veri toplama yöntemi olarak kullanılmaktadır. Veri toplama yaklaşımı olarak gözlem kullanmanın tarihi 1879'da Cushing'in Zuli halkı ile yaptığı dört buçuk yıllık çalışmaya kadar gider (Savin- Baden ve Major, 2013, 391). Günümüzde gözlem veri toplama aracı olarak yaygın bir şekilde kullanılmaktadır. 
Gözlem yoluyla araştırmacı katılımcıların günlük uygulamalarını belgeleyerek, onların deneyimlerini daha iyi anlamaya çalışır. Aslında gözlem ilk başta göründüğünden daha karmaşıktır. Çünkü araştırmacının katılımcılarla, neyi gözlemlediği, nerede gözlem yaptığı ve gözlem sürecinde hangi kararları aldığı ile ilgili duyguları ve düşüncelerini içerir (Savin- Baden ve Major, 2013, 392). Bu yaklaşım özellikle doğal ortamında herhangi bir olgunun neden ve nasıl olduğunu anlama ile ilgilidir. Gözlem ayrıca fiziksel çevrenin araştırma üzerindeki etkisi ile ilgili bilgi de verir. Gözlem kişilerin kendi söyledikleri ile gerçekte yaptıkları arasında farklılık olma olasılığına karşı etkili bir veri toplama yaklaşımı olabilir. Örneğin sınıfta yapılan gözlemler için açıklığa kavuşturulması gereken en az üç anahtar parametre vardır. Bunlar, gözlemci, gözlemin amaçları ve yöntemlerdir, bir başka ifadeyle, kim, neden ve nasıl sorularının cevaplarıdır (McDonough ve McDonough, 2006, 102). Bu soruların cevapları başarı testlerinin sonuçları ya da yeni öğretim yöntemleri ile verilemez (Eisner, 1998, 11).

Bu yöntem, eğitim araştırmalarında yaygın olarak kullanılan bir yöntemdir. Katılımcı belirli bir ortamda neler olduğunu gözlemlemeye ve kaydetmeye çalışır, fakat gözlemlenen aktivitelere aktif bir şekilde dahil olmaz (Menter ve diğerleri, 2011, 167). Başka bir ifadeyle, bu yaklaşımda araştırmacı kendi sınıfında ya da başka bir sınıfta neler olduğunu gözlemler. Bütün kişisel ilişkiler ve yaşam alanlarında bulunmasına rağmen, araştırmacı müdahaleci değildir. Kendi hipotezlerini test etmek için durumlar yaratmaz (Stake, 1995, 44). Gözlem süresince araştırmacı mümkün olduğunca dikkat çekici olmamalı, kendi halinde olmalı ve çalışılan konunun anlamını değiştirmekten kaçınmalıdır (Menter ve diğerleri, 2011, 168). Bu yaklaşımın temel özelliği duvardaki bir sinek gibi hareket etmek ve mümkünse normal akışındaki öğretim ve etkileşimi etkilememektir. (McDonough, Shaw ve Masuhara, 2013, 272). Aksi durumlarda, araştırmacının varlığı çalışılan ortamdaki insanların davranışlarını değiştirebilir. $\mathrm{Bu}$ değişikliklere "gözlemci etkisi" ya da "Heisenberg etkisi" denir (Bogdan ve Biklen, 1998, 35). Heisenberg elektron mikroskobunun 1sısının elektronların daha hızlı hareket etmesine sebep olduğunu keşfetmiştir. Bu mikroskop olmadan elektronlar daha yavaş hareket etmektedir. Bu nedenle, bu pahalı deneysel ekipmanı kullanmak bile, herhangi bir şeyin üzerinde etki bırakmadan çalışılamayacağını göstermektedir.

Sınıflarda sıklıkla gözlem yapılır. Gözlem yapmanın bir başka yolu da video kayıt yapmaktır. Fakat bir sınıfta oturarak video kaydı yapmak hiçbir zaman doğal bir davranış değildir. Çünkü sınıfta aşina olunmayan bir şeyin varlığı etkileşimin normal doğasını bozabilir (McDonough, Shaw ve Masuhara, 2013, 272). Diğer taraftan, sabit bir kamera sadece belirli bölgeleri kaydederken, hareketli kamera ise neyi kaydetmek istediğini seçecek bir operatör gerektirir. Öğretmenin sınıfın ortasında durduğu, öğrenci öğretmen ilişkisini kaydeden kısmen basit bir kayıtta bile resmin tamamını görmek, kaydetmek oldukça zordur (McDonough ve McDonough, 2006, 110). Bu bağlamda sınıf gözlemleri not edilerek kayıt altında tutulabilir (Walford, 2005, 86). İlk günlerde gözlem süresi bir saat ya da daha az olmalıdır. 
Ortamla ilgili güven ve bilgi arttıkça, gözlem için geçirilen süre de artabilir. Alan çalışması yapmak düşünülenden daha eğlencelidir bu nedenle araştırmacılar genellikle planladıklarından daha uzun süre alanda kalmayı tercih ederler (Bogdan ve Biklen, 1998, 93). Yapılacak gözlemin süresi araştırma yaklaşımının normlarına bağlı olarak birkaç hafta ya da ay gibi kısa süreli de olabilir (Savin- Baden ve Major, 2013, 393).

Gözlem, görüşme gibi diğer yöntemlerle üçgenlenerek, konuları, problemleri, uygulamaları ve insanları daha derinden anlayabilmek için doğal ortamlarında bilgi elde edilmesini sağlar (Menter ve diğerleri, 2011, 169).

\section{Sonuç}

Nitel araştırmalarda, büyük resmi ortaya koyabilmenin yollarından birisi üçgenleme yapmaktır. Büyük resmin ortaya konulması demek, durum tespitlerinin doğru yapılması, yanlış anlama ve algıların önlenmesi ve elde edilen verilerin geçerli ve güvenilir olması anlamına gelmektedir. Bu nedenle bu çalışmada, nitel araştırmalarda kullanılan odak grup görüşmeleri, bireysel görüşmeler ve gözlemler tanıtılmış ve veri üçgenlemesi olarak nasıl kullanıldığı betimlenmeye çalışılmış olup kavramsal bir çözümleme yapılmıştır.

Nitel araştırmalarda, odak grup görüşmesi, bireysel görüşme ve gözlemin tek başlarına mucizevi bir yöntem olduğu düşünülmemelidir. Nitel araştırmalarda inandırıcılık, geçerlik ve güvenirlik önceliklidir. Bu nedenle tek bir veri toplama yöntemi yerine çoklu yöntemlerin kullanılması tercih edilmelidir. Bir nitel araştırma yapıldığında doğal ortamlar bulunuyorsa, iç ve dış etkenlerin rol oynayacağı düşünülüyorsa bu üç teknik tercih edilebilir. Bu yöntemlerden elde edilen veriler karşılaştırıldığında birinde olan eksiklik, yanlışlık ve yanlış algı düzeltilebilir ve veriler daha iyi anlamlandırılabilir.

Hiçbir yöntem devam etmekte olan insan deneyimlerinin değişkenlerini her yönüyle ortaya koyamaz (Denzin ve Lincoln, 1998, 29; Wengraf, 2001, 51). Ancak, veri elde etmede birden fazla yöntem kullanmak bu deneyimlerin daha detaylı anlaşılabilmesine, bulguların karşılaştırılmasına ve çapraz kontrol yapılmasına yardım eder (Atkins ve Wallace, 2012, 111). Farklı yöntemlerle toplanan veriler aynı şeyi ifade ediyorsa, bulguların güvenirliği artar. Üçgenleme kullanılarak çoklu kaynaklardan sağlanan veri yapı geçerliğine farklı bir form sunar (Naumes ve Naumes, 1999, 59). Bu bağlamda eğitim alanında nitel araştırmalarda veri üçgenlemesi kullanılması önemlidir. Nitel araştırmalar sonsuz bir şekilde yaratıcı ve yorumlayıcıdır. Bu nedenle verilerin geçerli ve güvenilir olması gerekir. Bunun için araştırmalarda veri üçgenlemesi olarak odak grup görüşmeleri, bireysel görüşmeler ve gözlemler birlikte kullanılabileceği gibi farklı üçgenlemelerden de yararlanılabilir. 


\begin{abstract}
Nitel araştırmalarda verilerin toplanmasında kullanılabilecek dört temel yöntemden üçünü odak grup görüşmesi, görüşme ve gözlem olarak belirtmektedir (Çokluk, Yılmaz ve Oğuz, 2011). Odak grup görüşmesi, bireysel görüşme ve gözlem yöntemi, daha çok durum çalışması, eylem araştırması ve olgubilim araştırmalarında öncelikli olarak kullanılabilir. Bu yöntemlerin birlikte aynı araştırmada kullanılması durumunda gözlemin sürekli devam etmesi ve araştırmanın amacına bağlı olarak önce odak grup görüşmesi ve sonra da buradan ortaya çıkan ve bireysel derinlemesine sorulamayan soruları da yarı yapılandırılmış sorular çerçevesinde iletmek amacıyla bireysel görüşmeler gerçekleştirilebilir.
\end{abstract}

\title{
3.Kaynakça
}

Albrecht, T. L., Johnson, G. M. \& Walther, J. B. (1998). Understanding communication processes in focus groups, David L. Morgan (Ed) (pp. 51-62). Successful focus groups: Advancing state of the art. Newbury Park, Sage Publications.

Akar, H. (2016). Durum çalışması, Ahmet Saban ve Ali Ersoy (Ed.) (ss. 139-176). Eğitimde nitel araştırma desenleri. Ankara, Anı Yayıncılık.

Atkins, L. \&Wallace, S. (2012). Qualitative research in education. London, Sage Publications.

Bal, H. (2016). Nitel araştırma yöntem ve teknikleri (Uygulamalı örnekli). (1. Basım). İstanbul, Sentez Yayınları.

Bogdan, R. C. \& Biklen, S. K. (1998). Qualitative research for education: An introduction to theory and methods (3rd Edition). Boston, Allyn and Bacon.

Çokluk, Ö.; Yılmaz, K. ve Oğuz, E. (2011). Nitel bir görüşme yöntemi: Odak grup görüşmesi. Kuramsal Eğitimbilim, 4 (1), 95-107.

Denzin, N. K. ve Lincoln, Y. S. (1998). Introduction: Entering the field of qualitative research, Norman K. Denzin and Yvonna S. Lincoln (Ed.) (pp. 1-35). Strategies of qualitative inquiry. Thousand Oaks, Sage Publications.

Eisner, E. W. (1998). The enlightened eye: Qualitative inquiry and the enchancement of educational practice. New Jersey, Prentice Hall.

Kamberelis, G. \& Dimitriadis, G. (2005). Focus groups: Strategic articulations of pedagogy, politics, and inquiry, Norman K. Denzin \& Yvonna S. Lincoln (Ed) (pp. 887-907). The sage handbook of qualitative research (3rd Edition). Thousand Oaks, Sage Publications. 
Knodel, J. (1993). The design and analysis of focus group studies, David L. Morgan (Ed) (pp. 35- 50). Successful focus groups: Advancing state of the art. Newbury Park, Sage Publications.

Krueger, A. R. (1998). Quality control in focus group reserach, David L. Morgan (Ed.). (pp. 63- 74). Successful focus groups: Advancing state of the art. Newbury Park, Sage Publications.

Mayring, P. (2011). Nitel sosyal araştırmaya giriş (Çev. A. Gümüş ve M. S. Durgun). Ankara (1990).

McCormick, R. \& James, M. (1990). Curriculum evaluation in schools (3rd Edition). London, Routledge.

McDonough, J. \& McDonough, S. (2006). Reserach methods for English language teachers (3rd Edition). London, Arnold.

McDonough, J., Shaw, C. \& Masuhara, H. (2013). Materilas and methods in ELT: A teacher's guide (3rd Edition). Chichester, Wiley Blackwell Publishing.

Menter, I., Eliot, D., Hulme, D., Lewin, J. \& Lowden, K. (2011). A guide to practitioner research in education. London, Sage Publications.

Merriam, S. B. (2015). Nitel araştırma: Desen ve uygulama için bir rehber (3. Basımdan Çeviri) (Çev. Ed. S. Turan). Ankara (2009).

Merriam, S. B. (2009). Qualitative research: A guide to design and implementation; Revised and expanded from qualitative research and case study applications in education. San Francisco, JosseyBass A Wiley Imprint.

Mertens, D. (2005). Research and evaluation in education and psychology: Integrating diversity with quantitative, qualitative, and mixed methods (2nd Edition). Thousand Oaks, Sage Publications.

Morgan, D. L. \& Krueger, R. A. (1993). When to use focus groups and why, David L. Morgan (Ed) (pp. 3-19). Successful focus groups: Advancing state of the art. Newbury Park, Sage Publications.

Naumes, W. \& Naumes M. J. (1999). The art and craft of case writing. Thousand Oaks, Sage Publications.

Neuman, W. L. (2014). Social research methods: Qualitative and quantitive approaches (7th Edition). Essex, Pearson Education Limited.

O’Donoghue, T. (2007). Planning your qualitative research project: An introduction to interpretivist research in education. London, Routledge Taylor and Francis Group. 
Savin-Baden, M. \& Major, C. H. (2013). Qualitative research: The essential guide to theory and practice. London, Routledge Taylor and Francis Group.

Seidman, I. (2006). Interviewing as qualitative research: A guide for researchers in education and the social sciences (3rd Edition). New York, Teachers College Press.

Stake, R. E. (1995). The art of case study research. Thousand Oaks, Sage Publications.

Stake, R. E. (1998). Case studies, Norman K. Denzin and Yvonna S. Lincoln (Ed.) (pp. 86- 104). Strategies of qualitative inquiry. Thousand Oaks, Sage Publications.

Stake, R. E. (2005). Qualitative case studies, Norman K. Denzin and Yvonna S. Lincoln (Ed.) (pp. 443465). The sage handbook of qualitative research (3rd Edition). Thousand Oaks, Sage Publications.

Stewart, D. W. \& Shamdasani, P. N. (1990). Focus groups: Theory and practice (1st Edition). Newbury Park, Sage Publications.

Walford, G. (2005). Doing qualitative educational research: A personal guide to the research process (2nd Edition). London, Continuum.

Wengraf, T. (2001). Qualitative research interviewing: Biographic narrative and semi-structured methods (1st Edition). London, Sage Publications.

White, R. V. (1988). The ELT curriculum: Design, innovation and management (1st Edition). Oxford, Basil Blackwell Ltd.

Yıldırım, A. ve Şimşek, H. (2008). Sosyal bilimlerde nitel araştırma yöntemleri (6. Baskı). Ankara, Seçkin Yayıncılık 


\section{Extended Abstract}

Qualitative studies, frequently used in educational researches nowadays, are interested in how people interpret their own experience, how they construct their own worlds and which meanings they put their experience on. Qualitative studies have their own features. They are naturalistic, defining, engaged in the process, inductive and meaning focused studies. In qualitative studies, real situations are direct sources of data and the researcher is the key instrument. Gathered data are as vocabulary or pictures more than numbers. These data are included transcripts, field notes, photographs, video records, personal documents or other official records. In qualitative studies the result or the product is not important; the process is important. Qualitative researchers analyse the data inductively. Meaning is vital in qualitative studies. Qualitative researchers are interested in how different people lead their lives and being sure they capture different people's perspectives accurately. In order to minimize misunderstanding and results' invalidity, triangulation is used in qualitative studies. Triangulation is used to maximise the accuracy. The most common triangulation type used in social sciences is data triangulation, which consider the same phenomenon with different measuring approaches. In this sense focus group interviews, interviews and observations are used as data triangulation in qualitative studies. Focus group interviews make the researcher understand the social interactions during the process. They are constructed in a certain way and have well defined aims. Focus groups generally consist of eight or ten people and a moderator. A subject matter is given and the attendants are encouraged to talk about the subject first one by one, then as a part of the group dialogue. In individual interviews, an interviewer asks a question to another person to gain information. Interviews are used to gain descriptive data from the attendants' own words. Therefore; the researcher has a chance to gain insight related to how the attendants interpret their own worlds. To interview provides the researchers understand the human behaviour within the contexts and enables them to understand the meaning lying under their behaviour. Interviews should be carried on the attendant's workplace. In this way, he/she feels more secure. When the attendant is asked to express the world he/she experiences with his/her own views, less structured techniques and open-ended questions should be asked. A good interview is full of rich data which reveal the attendants' perspectives. In observations, the researcher documents the attendants' daily practices and try to understand better their experience. In fact, observations are much more complicated than they are seen. Because, they include some emotions and thoughts about what the researcher observes, where the observation is carried out and which decisions are taken in the course of the observation. For example, there are at least three parameters to be revealed in an observed classroom. These are the observer, the aim of the observation and the methods, in another word, the answers to who, why and how questions. The answers to these questions cannot be given with the results of success tests or new instructional methods. The answer to "what is happening at schools?" question can exactly be found via natural observation. To use more than one method to gain data helps to gain insight and helps the findings be compared and cross-controlled. When data which are gathered in different methods mean the same, the validity of findings are increases. Data which are gathered by multiple sources using triangulation presents a different perspective to validity. In conclusion, qualitative researchers use a series of interpretive methods, connected with each other, and try to find out more explanatory ways to help experienced worlds be understood better. Qualitative studies are infinitely creative and interpretive. 